\title{
Is Stylet Use During Intubation Associated with Post Intubation Complications
}

\author{
Talha Tariq ${ }^{1} \quad$ Syeda Farzana Batool Zaidi ${ }^{2} \quad$ Moalla Muzzafar ${ }^{3}$ \\ 1.House Officer Nishtar Hospital, Multan \\ 2.Consultant Anaesthetist \\ Ch. Pervaiz Ellahi Institute of Cardiology, Multan \\ 3. Resident Plastic Surgery, Alnoor Hospital, Makkah KSA
}

\begin{abstract}
Objective: The basic objective is to evaluate the impacts of placing stylet during tracheal intubation on the postoperative pharyngeal pain in anesthetized patients. Methodology: This randomized control trail was conducted in the department of Anesthesia and ICU, Ch. Pervaiz Ellahi Institute of Cardiology and Nishter Hospital Multan from May 2017 to December 2018. All these patients were divided into two groups group S (stylet group) and group $\mathrm{C}$ (control group) by lottery method. All the data was entered and analyzed by the computer software SPSS version 23.2. Results: A total number of $100 \%(n=386)$ patients were included in this study, both genders. Gender distribution showed that there were more males than females i.e. $56.2 \%(\mathrm{n}=217)$ and $43.8 \%$ $(n=169)$ respectively. The main outcome variables of this study were pharyngeal pain, airway maintenance and sore throat. It was also noted that group $(\mathrm{S})$ showed easy airway maintenance in $95.9 \%(\mathrm{n}=185)$ patients. It was observed that, in group $(\mathrm{S}), 63.2 \%(\mathrm{n}=122)$ patients were complained from sore throat and $67.4 \%(\mathrm{n}=130)$ were complained about pharyngeal pain. While on the other hand, in group $(\mathrm{C})$, only $8.3 \%(\mathrm{n}=16)$ patients were complained about sore throat and $11.4 \%(\mathrm{n}=22)$ were complained about pharyngeal pain Conclusion: Use of stylet during endotracheal intubation decreases the incidences multiple attempts and make the airway maintenance easy for the anesthetist but on the other side it have complications like sore throat and post intubation pharyngeal pain than those patients in which stylet was not usede.
\end{abstract}

Keywords: Pharyngeal pain, Tracheal Intubation, Stylet, Post-operative.

DOI: $10.7176 / \mathrm{JMPB} / 53-05$

Publication date:March $31^{\text {st }} 2019$

\section{Introduction}

Tracheal intubation is very well known and useful procedure in the general anesthesia(1). It is usually simply referred as to place the flexible plastic tube into the trachea (windpipe) to maintain the open air passage $(2,3)$. In 1979 Ketz and Berci(4) used a term optical stylet for a straight and rigid device which is helpful in Endotracheal intubation. This is very helpful in early airway maintenance. Size of stylet always constant and it should be equal to size of minimum endotracheal tube(5).

Stylets are designed to allow oxygen passage, route for drug administration and suction facility because as diameter of stylet increases size of tracheal tube shortens(6). In difficult airways it is very helpfull to reduce number of attempts for intubation and easy airway management(7). Efficacy of styles and anesthetist satisfaction about has been reported in many studies, but at the same time it was reported that light obstruction with secretion increase the number attempts. Patients should be asked for coughing and huffing properly in pre intubation time to avoid hurdles due to secretions.

Contrary to this, pharyngeal pain and sore throat are very common and usual complaints of post-intubation. One of the major contributing factors is the tracheal intubation that could cause the pathological changes, trauma and nerve damage of trachea and air passage as well(8). It has following important uses: it guides the tracheal tube directly to the larynx, allows the tracheal tube to pass easily, can be stiffened to help tracheal tube to pass through trachea. Shape of stylet can be modified to facilitate the tracheal intubation(9).

In a study Nobuyasu et al (10) suggested that the stylet use in the tracheal intubation is very contributing in the post-operative pharyngeal pain. According to this, there was significantly. Raised post-operative pharyngeal pain in the stylet group $(10 / 20$ patients $)$ than in the control group $(2 / 20$ patients $)(P=0.013)$. Similarly most of the previous studies are not in favor of stylet use during the endotracheal intubation but many previous studies also suggest the use of stylet.

Few studies have been conducted on this topic before and almost all were on a small sample size. Another gap in previous studies is that they were conducted on single aspect of device benefits or or complication. But in our study we evaluate both aspect and our study was on a large sample size.

\section{Methodology}

This randomized control (RCT) was conducted in the the department of Anesthesia and ICU, Ch. Pervaiz Ellahi Institute of Cardiology and Nishter Hospital Multan from May 2017 to December 2018.. After taking the 
ethical approval from the institutional ethical committee of hospital study was started. Informed consent from the particular subjects was also taken. After this we enrolled total number of $386(100 \%)$ patients. Sample size was calculated from WHO's website sample calculation for two proportions with following figures CI 95\%, Power, $80 \%$, P1 50\% and P2 6.66 (10). Patients need endotracheal intubation with help of stylet, from age group 15-45 years of both genders were included in the study, while patients with congenital abnormalities, ENT, oral surgery, facial injury, and above, and those in which endotracheal not placed for general anesthesia were excluded from study.

Patient meeting the endotracheal criteria were Intubating with endotracheal tube of standard size calculated 7 ID for females and 7.5 ID for males by anesthesiologist having an experience of at least 5 years. After placement of endotracheal tube to the patient, cuff was inflated with air by auscultating trachea with minimal audible air leak. Standard conducts of anesthesia with monitoring as suggested were observed. After extubation patients were interviewed about their pharyngeal pain and sore throat when gain the orientation and consciousness. Pharyngeal pain was graded as Grade 0 - No pain, Grade 1 - Mild Pain, Grade 2 - Moderate pain, Grade 3 - severe pain as described by the patients.

All variables like, Age, Gender, BMI, easiness in airway maintenance, Pharyngeal pain and sore throat were noted in the Pre- designed Performa and analyzed by using SPSS 23.2 V. Mean + SD calculated for quantitative variables and frequency percentages for qualitative variables. P value 0.05 was considered as significant.

\section{Results}

A total number of $100 \%(n=386)$ patients were included in this study, both genders. Gender distribution showed that there were more males than females i.e. $56.2 \%(\mathrm{n}=217)$ and $43.8 \%(\mathrm{n}=169)$ respectively. The mean age and BMI of the patients was $35.03 \pm 9.82$ years and 28.45 \pm 4.60 BMI respectively. The distribution of Mallum Patti grades (1-4) showed that 33.4\% $(\mathrm{n}=129)$ patients had grade $1,17.1 \%(\mathrm{n}=66)$ had grade $2,38.1 \%(\mathrm{n}=147) \mathrm{had}$ grade 3 and only $11.4 \%(n=44)$ patients had grade 4 .

When patients were categorized into different age and BMI categories, it was noted that majority of patients i.e. $52.3 \%(n=202)$ were aged from 15 to 35 years and $47.7 \%(n=184)$ were aged from 36 to 63 years. $56 \%$ $(\mathrm{n}=216)$ patients were BMI from 22 to 28 and 44\% $(\mathrm{n}=170)$ patients were BMI from 29 to 36 respectively.

These $100 \%(n=386)$ patients were divided into 2 groups, 193 in each, i.e. control $(\mathrm{C})$ and stylet (S). The mean age and BMI of the patients of control group was $35.16 \pm 9.98$ and $32.46 \pm 2.76$ respectively, while the mean age and BMI of the patients of stylet group 34.91 \pm 9.69 and $24.44 \pm 1.58$ respectively.

The main outcome variables of this study were pharyngeal pain, airway maintenance and sore throat. It was observed that, in group $(\mathrm{S}), 63.2 \%(\mathrm{n}=122)$ patients suffered from sore throat and $67.4 \%(\mathrm{n}=130)$ suffered from pharyngeal pain. It was also noted that group $(\mathrm{S})$ showed easy airway maintenance in $95.9 \%(\mathrm{n}=185)$ patients and difficult airway maintenance in $4.1 \%(n=8)$. While on the other hand, in group (C), only $8.3 \%(n=16)$ patients suffered from sore throat and $11.4 \%(n=22)$ suffered from pharyngeal pain. It was also observed that group (C) showed easy airway maintenance in $78.2 \%(\mathrm{n}=151)$ patients and difficult airway maintenance in $21.8 \%(\mathrm{n}=42)$ patients.

When Chi-Square was applied to check the association, it was noted that sore throat was significantly associated with stratified age, BMI, Mallum Patti grades and groups with p-values 0.000, 0.000, 0.000 and 0.000 respectively. But it was not associated with gender with p-value 0.344 .

Similarly, when Chi-Square was applied to check the association, it was noted that pharyngeal pain was significantly associated with stratified age, BMI, Mallum Patti grades and groups with p-values 0.000, 0.000, 0.000 and 0.000 respectively. But it was not associated with gender with p-value 0.073 .

Similarly, when Chi-Square was applied to check the association, it was noted that airway maintenance was significantly associated with stratified age, BMI, Mallum Patti grades and groups with p-values 0.000, 0.000, 0.000 and 0.000 respectively. But it was not associated with gender with p-value 0.735 . 
Table- 1 Demographic Variables:(n=386)

\begin{tabular}{|c|c|c|}
\hline Characteristics & Frequency & Percentage (\%) \\
\hline \multicolumn{3}{|l|}{ Gender } \\
\hline Male & 217 & 56.2 \\
\hline Female & 169 & 43.8 \\
\hline Total & 386 & 100.0 \\
\hline \multicolumn{3}{|l|}{ Stratified Age } \\
\hline 15-35years & 202 & 52.3 \\
\hline 36-63 years & 184 & 47.7 \\
\hline Total & 386 & 100.0 \\
\hline \multicolumn{3}{|l|}{ Stratified BMI } \\
\hline $22-28$ & 216 & 56 \\
\hline $29-36$ & 170 & 44 \\
\hline Total & 386 & 100.0 \\
\hline \multicolumn{3}{|c|}{ Mallum Patti Grades } \\
\hline Grade 1 & 129 & 33.4 \\
\hline Grade 2 & 66 & 17.1 \\
\hline Grade 3 & 147 & 38.1 \\
\hline Grade 4 & 44 & 11.4 \\
\hline Total & 386 & 100.0 \\
\hline \multicolumn{3}{|c|}{ Descriptive Statistics } \\
\hline & Mean & S.D \\
\hline Age in years & 35.03 & 9.82 \\
\hline BMI & 28.45 & 4.60 \\
\hline
\end{tabular}

Table 2: Mean \pm S.D in Groups

\begin{tabular}{|c||c|c|}
\hline Groups & variables & Mean \pm S.D \\
\hline \hline \multirow{2}{*}{ Group (S) } & Age in years & $34.91 \pm 9.69$ \\
\cline { 2 - 3 } & BMI & $24.44 \pm 1.58$ \\
\hline \hline \multirow{2}{*}{ Group (C) } & Age in years & $35.16 \pm 9.98$ \\
\cline { 2 - 3 } & BMI & $32.46 \pm 2.76$ \\
\hline
\end{tabular}

Table 3:

\begin{tabular}{|c|c|c|c|}
\hline \multicolumn{4}{|c|}{ Pharyngeal Pain } \\
\hline Groups & Presence & Frequency & Percent \\
\hline \multirow[t]{3}{*}{ Group (S) } & Yes & 130 & 67.4 \\
\hline & No & 63 & 32.6 \\
\hline & Total & 193 & $10 \mathbf{1 0 0 . 0}$ \\
\hline \multirow[t]{3}{*}{ Group (C) } & Yes & 22 & 11.4 \\
\hline & No & 171 & 88.6 \\
\hline & Total & 193 & 100.0 \\
\hline \multicolumn{4}{|c|}{ Sore throat } \\
\hline \multirow[t]{3}{*}{ Group (S) } & Yes & 122 & 63.2 \\
\hline & No & 71 & 36.8 \\
\hline & Total & 193 & 100. \\
\hline \multirow[t]{3}{*}{ Group (C) } & Yes & 16 & 8.3 \\
\hline & No & 177 & 91.7 \\
\hline & Total & 193 & 100.0 \\
\hline \multicolumn{4}{|c|}{ Airway Maintenance } \\
\hline \multirow[t]{3}{*}{ Group (S) } & Easy & 185 & 95.9 \\
\hline & Difficult & 8 & 4.1 \\
\hline & Total & 193 & 100.0 \\
\hline \multirow[t]{3}{*}{ Group (C) } & Easy & 151 & 78.2 \\
\hline & Difficult & 42 & 21.8 \\
\hline & Total & 193 & 100.0 \\
\hline
\end{tabular}


Table No. 4

Association of Pharyngeal Pain with Effect Modifiers $(n=386)$

\begin{tabular}{|c|c|c|c|c|c|}
\hline \multirow{2}{*}{\multicolumn{2}{|c|}{ Effect Modifiers }} & \multirow{2}{*}{\multicolumn{2}{|c|}{ Pharyngeal Pain }} & \multirow{3}{*}{\begin{tabular}{|l|} 
Total \\
202 \\
\end{tabular}} & \multirow[t]{2}{*}{ P-value } \\
\hline & & & & & \\
\hline \multirow[t]{2}{*}{ Stratified Age } & $15-35$ years & 127 & 75 & & \multirow[t]{3}{*}{0.000} \\
\hline & 36-63 years & 25 & 159 & 184 & \\
\hline \multicolumn{2}{|c|}{ Total } & 152 & 234 & 386 & \\
\hline \multirow[t]{2}{*}{ Stratified BMI } & 22-28 BMI & 140 & 76 & 216 & \multirow[t]{3}{*}{0.000} \\
\hline & 29-36 BMI & 12 & 158 & 170 & \\
\hline \multicolumn{2}{|c|}{ Total } & 152 & 234 & 386 & \\
\hline \multirow[t]{2}{*}{ Gender } & Male & 94 & 123 & 217 & \multirow[t]{3}{*}{0.073} \\
\hline & Female & 58 & 111 & 169 & \\
\hline \multicolumn{2}{|c|}{ Total } & 152 & 234 & 386 & \\
\hline \multirow{4}{*}{$\begin{array}{l}\text { Mallum Patti } \\
\text { grades }\end{array}$} & 1 & 8 & 121 & 129 & \multirow[t]{5}{*}{0.000} \\
\hline & 2 & 14 & 52 & 66 & \\
\hline & 3 & 25 & 122 & 147 & \\
\hline & 4 & 32 & 12 & 44 & \\
\hline \multicolumn{2}{|c|}{ Total } & 152 & 234 & 386 & \\
\hline \multirow[t]{2}{*}{ Groups } & Group (S) & 130 & 63 & 193 & \multirow[t]{3}{*}{0.000} \\
\hline & Group (C) & 22 & 171 & 193 & \\
\hline \multicolumn{2}{|c|}{ Total } & 152 & 234 & 386 & \\
\hline
\end{tabular}

Table No. 5

Association of Sore Throat with Effect Modifiers

\begin{tabular}{|c|c|c|c|c|c|}
\hline \multirow{2}{*}{\multicolumn{2}{|c|}{ Effect Modifiers }} & \multirow{2}{*}{\multicolumn{2}{|c|}{ Sore Throat }} & \multirow{3}{*}{\begin{tabular}{|c|} 
Total \\
202 \\
\end{tabular}} & \multirow{4}{*}{\begin{tabular}{|c|} 
P-value \\
$\mathbf{0 . 0 0 0}$ \\
\end{tabular}} \\
\hline & & & & & \\
\hline Stratified Age & $15-35$ years & $\begin{array}{l}\text { Yes } \\
121 \\
\end{array}$ & $\begin{array}{c}\text { No } \\
81 \\
\end{array}$ & & \\
\hline & $36-63$ years & 17 & 167 & 184 & \\
\hline \multicolumn{2}{|c|}{ Total } & 138 & 248 & 386 & \\
\hline \multirow[t]{2}{*}{ Stratified BMI } & 22-28 BMI & 132 & 84 & 216 & \multirow[t]{3}{*}{0.000} \\
\hline & 29-36 BMI & 6 & 164 & 170 & \\
\hline \multicolumn{2}{|c|}{ Total } & 138 & 248 & 386 & \\
\hline \multirow[t]{2}{*}{ Gender } & Male & 82 & 135 & 217 & \multirow[t]{3}{*}{0.344} \\
\hline & Female & 56 & 113 & 169 & \\
\hline \multicolumn{2}{|c|}{ Total } & 138 & 248 & 386 & \\
\hline \multirow{4}{*}{$\begin{array}{l}\text { Mallum Patti } \\
\text { grades }\end{array}$} & 1 & 27 & 105 & 129 & \multirow[t]{5}{*}{0.000} \\
\hline & 2 & 33 & 33 & 66 & \\
\hline & 3 & 38 & 109 & 147 & \\
\hline & 4 & 40 & 4 & 44 & \\
\hline \multicolumn{2}{|c|}{ Total } & 138 & 248 & 386 & \\
\hline \multirow[t]{2}{*}{ Groups } & Group (S) & 121 & 71 & 193 & \multirow[t]{3}{*}{0.000} \\
\hline & Group (C) & 16 & 177 & 193 & \\
\hline \multicolumn{2}{|c|}{ Total } & 138 & 248 & 386 & \\
\hline
\end{tabular}


Table No. 6

Association of Airway Maintenance with Effect Modifiers

$(\mathbf{n}=\mathbf{3 8 6})$

\begin{tabular}{|c|c|c|c|c|c|}
\hline \multicolumn{2}{|c|}{ Effect Modifiers } & \multicolumn{2}{|c|}{ Sore Throat } & \multirow{3}{*}{$\begin{array}{c}\text { Total } \\
202 \\
\end{array}$} & \multirow{2}{*}{ P-value } \\
\hline & & Easy & Difficult & & \\
\hline \multirow{2}{*}{ Stratified Age } & 15-35 years & 197 & 5 & & \multirow{3}{*}{0.000} \\
\hline & $36-63$ years & 139 & 45 & 184 & \\
\hline \multicolumn{2}{|c|}{ Total } & 336 & 50 & 386 & \\
\hline \multirow[t]{2}{*}{ Stratified BMI } & 22-28 BMI & 208 & 8 & 216 & \multirow[t]{3}{*}{0.000} \\
\hline & 29-36 BMI & 128 & 42 & 170 & \\
\hline \multicolumn{2}{|c|}{ Total } & 336 & $\mathbf{5 0}$ & 386 & \\
\hline \multirow[t]{2}{*}{ Gender } & Male & 190 & 27 & 217 & \multirow[t]{3}{*}{0.735} \\
\hline & Female & 146 & 23 & 169 & \\
\hline \multicolumn{2}{|c|}{ Total } & 336 & $\begin{array}{c}\mathbf{5 0} \\
\end{array}$ & 386 & \\
\hline \multirow{4}{*}{$\begin{array}{c}\text { Mallum Patti } \\
\text { grades }\end{array}$} & 1 & 122 & 7 & 129 & \multirow[t]{5}{*}{0.000} \\
\hline & 2 & 55 & 11 & 66 & \\
\hline & 3 & 133 & 14 & 147 & \\
\hline & 4 & 26 & 18 & 44 & \\
\hline \multicolumn{2}{|c|}{ Total } & 336 & 50 & 386 & \\
\hline \multirow[t]{2}{*}{ Groups } & Group (S) & 185 & 8 & 193 & \multirow[t]{3}{*}{0.000} \\
\hline & Group (C) & 151 & 42 & 193 & \\
\hline & & 336 & $\overline{50}$ & 386 & \\
\hline
\end{tabular}

\section{Discussion}

For last many years, instead of having many side effects on the air passage and tracheal passage but tracheal intubation procedure is still being used separately and with help of stylet as well. Because still the anesthesiologists think it as useful and very helpful but none of any other procedure has not replaced it properly till now $(11,12)$.

In our study it was noted that group $(\mathrm{S})$ showed easy airway maintenance in $95.9 \%(\mathrm{n}=185)$ patients and difficult airway maintenance in $4.1 \%(n=8)$. In two previous studies 35 patients were intubated, out of these 11 patients were with difficult airway due to anatomical curvature and lot of secretions but they were all intubated successfully, success rate was $100 \%(13)$. In another study a special type of stylet named as styletoscope was used and tried on difficult airways. It was reported that $94 \%$ difficult airways were intubated successfully after one attempt and $100 \%$ after two attempts. In this study it was also reported that mallampati score have no effect on intubation time and number of attempts (14).

In our study we observed that, in group $(\mathrm{S}), 63.2 \%(\mathrm{n}=122)$ patients were complained from sore throat and $67.4 \%(n=130)$ were complained about pharyngeal pain. While on the other hand, in group (C), only $8.3 \%$ $(\mathrm{n}=16)$ patients were complained about sore throat and $11.4 \%(\mathrm{n}=22)$ were complained about pharyngeal pain. In another study conducted by John C et al (9) on effect of stylet use on succesfull intubation rate and reported that successful airway management and intubation rate was $82.9 \%$ with the use of stylet. But he also evaluated complications of stylet use as oxygen desaturation but he compared two types of stylets not stylet and control group. Results of these studies are comparable with our results.

But the previous study did by Nobuyasu Komasawa et al (10) suggested that the incidence of post-operative pharyngeal pain was raised in the stylet group (10/20 patients) about $50 \%$ than in the control group ( $2 / 30$ patients) about $6.6 \%$. This study shows identical results to our clinical trial.

Similarly, the previous study by El-Boghdadly K et al (15) suggested that sore throat in $50 \%$ patients and the hoarseness in 55\% patients were observed immediately after the surgery. Both the sore throat and the hoarseness were found even after the use of lidocaine spray. This is also mismatching of our study at all. In another study Salvalaggio et al(16) conducted a study and reported that intubation with the use of stylet have more complication like sore throat and horeness of voice (17). In another study Kitamura T et al(14) reported incidence of sore throat in $28 \%$ of patient with the use of stylet minor hoarseness in $25 \%$ patients. In some studies conducted by AM Christensen (18), Harding CJ (19), P Herlevsen (20) post intubation sore throat reported from 14.4 to $50 \%$ and after insertion of laryngeal mask airway it was 5.8 to $24 \%$.

Some previous studies shows the results of application of lubricant on the endotracheal tube in $(20 / 60)$ patients, the sore throat and pharyngeal pain were both significantly higher; but in our study we didn't use lubrication for endotracheal tube. 


\section{Conclusion}

Use of stylet during endotracheal intubation decreases the incidences multiple attempts and make the airway maintenance easy for the anesthetist but on the other side it have complications like sore throat and post intubation pharyngeal pain than those patients in which stylet was not usede.

\section{Recommendations}

In the spectrum of our clinical trial we are going to suggest using the stylet during every endotracheal intubation procedure for every difficult airway. But it enhances the incidence of the sore throat and pharyngeal pain in postoperative anesthetized patients, so it should be use in limited cases.

\section{Funding Sources:}

Nil

\section{Conflict of interest:}

Nil

\section{References}

1. Knudsen K, Nilsson U, Högman M, Pöder U. Awake intubation creates feelings of being in a vulnerable situation but cared for in safe hands: a qualitative study. BMC anesthesiology. 2016;16(1):71.

2. Herskovic JJ. Combined laryngo-tracheal anesthetic and stylet device. Google Patents; 2017.

3. Herskovic JJ. Combined laryno-tracheal anesthetic and stylet device. Google Patents; 2016.

4. Berci G, Katz R. Optical stylet: an aid to intubation and teaching. Annals of Otology, Rhinology \& Laryngology. 1979;88(6):828-31.

5. Applebaum E. Laryngeal and tracheal problems in patients with central nervous system and spinal disorders. Otolaryngologic clinics of North America. 1979;12(4):829-35.

6. Artime CA, Daily WH. The difficult airway: A practical guide: Oxford University Press; 2013.

7. Black AE, Flynn PE, Smith HL, Thomas ML, Wilkinson KA. Development of a guideline for the management of the unanticipated difficult airway in pediatric practice. Pediatric Anesthesia. 2015;25(4):346-62.

8. Hagberg C, Georgi R, Krier C. Complications of managing the airway. Best Practice \& Research Clinical Anaesthesiology. 2005;19(4):641-59.

9. Chuda RM. Intubation device with video and anatomic stylet steering. Google Patents; 2014.

10. Komasawa N, Nishihara I, Minami T. Effects of stylet use during tracheal intubation on postoperative pharyngeal pain in anesthetized patients: A prospective randomized controlled trial. Journal of Clinical Anesthesia. 2017;38:68-70.

11. Frerk C, Mitchell V, McNarry A, Mendonca C, Bhagrath R, Patel A, et al. Difficult Airway Society 2015 guidelines for management of unanticipated difficult intubation in adults. British journal of anaesthesia. 2015;115(6):827-48.

12. Angel LF. Airway assembly for tracheal intubation. Google Patents; 2014.

13. Pollack C, Bradley B, Jordon R, Mackin R, editors. clinical trial of a fiberoptic-enhanced endotracheal tube for intubation, monitoring, tube placement, confirmation and difficult airway management. Annual meeting of the Society for Academic Emergency Medicine, Washington DC; 1997.

14. Yamada Y, Kitamura T, Du H-L, Hanaoka K. An efficient technique for tracheal intubation using the StyletScope alone. The Journal of the American Society of Anesthesiologists. 2000;92(4):1210-.

15. El-Boghdadly K, Bailey C, Wiles M. Postoperative sore throat: a systematic review. Anaesthesia. 2016;71(6):706-17.

16. de Oliveira Salvalaggio MF, Rehme R, Fernandez R, Vieira S, Nakashima P. A comparative study between the laryngoscope and lighted stylet in tracheal intubation. Brazilian Journal of Anesthesiology. 2010;60(2):138-43.

17. Stone DJ, Stirt JA, Kaplan MJ, Mclean WC. A complication of lightwand-guided nasotracheal intubation. The Journal of the American Society of Anesthesiologists. 1984;61(6):780-.

18. Christensen A, Willemoes-Larsen H, Lundby L, Jakobsen K. Postoperative throat complaints after tracheal intubation. British Journal of Anaesthesia. 1994;73(6):786-7.

19. Harding C, McVey F. Interview method affects incidence of postoperative sore throat. Anaesthesia. 1987;42(10):1104-7.

20. Herlevsen P, Bredahl C, Hindsholm K, Kruhøffer P. Prophylactic laryngo-tracheal aerosolized lidocaine against postoperative sore throat. Acta anaesthesiologica scandinavica. 1992;36(6):505-7. 